\title{
Artigos
}

\section{A RELAÇÃO ENTRE ESPECTADOR E OBRA DE ARTE}

\author{
THE RELATIONSHIP BETWEEN SPECTATOR \\ AND WORK OF ART
}

LA RELACIÓN ENTRE EL ESPECTADOR

$Y$ LA OBRA DE ARTE

Karine Ramaldes 


\section{Resumo}

Neste estudo, a partir da pesquisa bibliográfica, faço a explanação de pontos que considero significativos na relação entre o espectador e a obra de arte, sendo eles: alguns termos mais utilizados para denominar essa relação espectador e obra de arte; a relevância do espectador na concretização da obra de arte; o processo de transformação simbólica da experiência do espectador. Meu objetivo é aprofundar os estudos relacionados ao assunto partindo de conceitos utilizados especialmente por John Dewey, Patrice Pavis e Susanne Langer.

Palavras-chave: Experiência, Interpretação da obra, Leitura da obra, Significação, Simbolização.

\section{Abstract}

From the literature search, I explain, in this study, points that I consider significant in the relationship between spectator and work of art, which are: some of the most commonly used terms to denote this relationship; the relevance of the spectator in the implementation of the work of art; the symbolic transformation process of the spectator experience. My goal is to deepen the studies related to the subject, starting from concepts used especially by John Dewey, Patrice Pavis, and Susanne Langer.

Keywords: Experience, Interpretation of the work, Reading of the work, Signification, Symbolization.

\section{Resumen}

Desde una búsqueda en la literatura, en este estudio se plantean aspectos, que considero significativos, en la relación entre el espectador y la obra: algunos de los términos más comúnmente utilizados para denotar esta relación —espectador y obra de arte; la relevancia del espectador en la ejecución de la obra de arte; el proceso de transformación simbólica de la experiencia del espectador. Con el objeto de profundizar en los estudios relacionados con el tema, se utilizan conceptos empleados especialmente por John Dewey, Patrice Pavis y Susanne Langer.

Palabras clave: Experiencia, Interpretación de la obra, Lectura de la obra, Significación, Simbolización. 
Diversas abordagens sobre o espectador têm sido realizadas em diferentes áreas de estudo, como a antropologia, a psicologia, a sociologia, as artes, dentre outras. Um dos motivos pelos quais essa relação tem sido estudada tão profundamente é que o espectador é figura fundamental para que uma obra de arte se concretize. Abordarei aqui a relação entre a obra de arte e o espectador a partir do campo de estudo das artes, fazendo relação direta com a arte teatral.

No contexto geral da arte, muito se tem discutido sobre quais são os termos mais adequados a se empregar quando nos referimos à relação entre o espectador e a obra de arte, entre os quais estão apreciar, fruir, interpretar e ler a obra de arte. De modo geral, os significados desses termos, segundo Borba (1990), Cunha (1982) e Houaiss e Villar (2009) se apresentam como: Apreciar já traz implícito o gostar e está diretamente ligado ao demonstrar admiração; fruir significa desfrutar prazerosamente, usufruir, ter prazer com algo, ou seja, é também relacionado a conceitos positivos; interpretar está mais relacionado a explicar o que é obscuro, dar significação a algo; ler é ter acesso a algo, compreender, ver o sentido de algo.

Cada um dos termos citados pode ser analisado com mais minúcia e, de início, já descarto dois deles: apreciar e fruir, que, nesse contexto de análise, não se adequariam, pois se apresentam com apenas uma possibilidade de relação com a obra de arte - a relação positiva. Compreendo que o espectador, ao estabelecer uma relação com a obra de arte (escultura, telas, cinema, espetáculo teatral etc.), pode demonstrar uma relação positiva e/ou negativa com a obra. Ao empregar os termos apreciar e fruir, já estamos induzindo o espectador a ter a visão contemplativa e positiva da obra, anulando, desse modo, as suas impressões reais.

Os termos interpretar e ler a obra de arte, a princípio, parecem ser mais apropriados para se referir à relação espectador e obra. Para Patrice Pavis ${ }^{1}$ (2007, p. 212), interpretação, no sentido aqui explanado, é: "Abordagem crítica pelo leitor ou pelo espectador do texto e da cena, a interpretação se preocupa em determinar o sentido e a significação. Ela concerne tanto ao processo da produção do espetáculo pelos 'autores' quanto ao de sua recepção pelo

1. Professor de teatro da Universidade de Paris. 
público.' Dessarte, os autores e artistas envolvidos na produção do espetáculo terão suas interpretações, que serão organizadas em forma de apresentação. Ao levar tal apresentação para os espectadores, diferentes interpretações surgirão por parte deles. Pavis (2007, p. 213) continua: "A interpretação organiza a diversidade das possíveis leituras de uma mesma obra". O autor, dessa maneira, afirma que os espectadores podem ter interpretações diferentes de uma mesma obra de arte, sendo que essas interpretações podem ser distintas também das concepções empregadas pelo diretor e pelos atores ao conceberem o espetáculo.

As significações de um espetáculo teatral depreendidas pelos espectadores podem e devem ser múltiplas, uma vez que ele consiste em uma obra de arte impregnada de concepções dos atores e diretor. Porém, o espectador, ao entrar em contato com essa obra de arte, estabelece uma relação entre suas experiências pessoais e as experiências apresentadas em cena, o que resulta em uma interpretação carregada de significados distintos, e é por causa da conexão dessas experiências individuais dos espectadores com a obra que surgem diferentes formas de interpretação. Como afirma Ferdinando Taviani, "é a divergência, a não coincidência ou até a falta de consciência recíproca entre a visão do ator e a visão do espectador (relativa a um mesmo espetáculo) que fazem do teatro uma arte, e não apenas uma imitação ou uma réplica do que já se conhece" (apud BARBA; SAVARESE, 2012, p. 300).

Quando falamos de arte, estamos falando de múltiplas possibilidades de interpretação, pois a arte não necessita ser literal, ela é múltipla de significações e de simbolizações. A obra de arte é expressiva, porém, a expressividade da obra de arte, na maioria dos casos, não permite uma transposição do seu entendimento para a fala. Não existem palavras capazes de descrever uma boa parte das obras de arte, já que elas se expressam por meio da sensação e da emoção. A arte manifesta significados que não percebemos comumente. Ao se transformar em obra de arte, a experiência do artista ganha corpo a partir da sensibilidade e da emoção.

O filósofo e educador John Dewey (1859-1952) (2010, p. 182) pontua: "A ciência afirma significados; a arte os expressa". Ao ratificar um significado, a ciência nos induz a compreender que uma verdade está estabelecida. Até que se prove o contrário, temos uma verdade generalizada, já que, na ciência, o 
conhecimento deve ser testado, ou seja, deve comprovar a sua veracidade a partir de métodos específicos e apresentar o resultado dessa verificação por meio de provas objetivas, de comprovações que, na maioria das vezes, são exatas, vindas de laboratórios. A arte, ao expressar significados, dá-nos possibilidades de várias interpretações de uma mesma obra, isto é, a arte não se encerra em um significado, mas em vários sentidos que vão depender das leituras realizadas pelos seus espectadores. Não existe uma generalização de significados na arte como na ciência, não se pode definir se uma obra de arte significa apenas tal representação, com a exatidão e objetividade da ciência - a arte envolve a subjetividade do artista e do espectador, e isso precisa ser considerado.

É necessário existir a tríade artista-obra-espectador para que uma obra se concretize. Dewey (2010, p. 215) afirma: "A obra de arte só é completa na medida em que funciona na experiência de outros que não aquele que a criou". Aqui, ele trata da relevância do espectador na concretização da expressividade da obra de arte, apontando o papel fundamental do espectador nessa relação típica da linguagem: aquele que fala, o objeto do qual se fala, aquele com quem se fala. No caso da obra de arte, eu diria que temos: aquele que cria a obra, a obra de arte, o espectador da obra. Uma obra de arte se completa na relação com o espectador, e, cada vez que alguém entra em contato com uma obra de arte, está tendo uma nova e única experiência.

Linguagem verbal e arte são formas de expressão humana; a primeira se manifesta de modo mais objetivo e a segunda se expressa a partir da sensação, da emoção, de modo mais subjetivo, mas ambas, para chegarem a uma forma expressiva, passam pela transformação simbólica da experiência, conceito apresentado por Susanne Langer ${ }^{2}$ (2004) que explanarei aqui: a arte, assim como a linguagem verbal, é uma forma de simbolização do ser humano. Langer (2004, p. 51) afirma que a necessidade básica de simbolização é uma necessidade apenas do homem, e continua: "A função de fazer símbolos é uma das atividades primárias do ser humano, da mesma forma

2. Susanne Langer (1895-1985), grande especialista em filosofia da arte e seguidora das ideias de Ernst Cassirer (1874-1945), filósofo alemão que desenvolveu um denso estudo sobre a filosofia das formas simbólicas, compreendendo o ser humano como um animal simbólico. 
que comer, olhar ou mover-se de um lado para o outro. É o processo fundamental de sua mente, e este continua o tempo todo" (LANGER, 2004, p. 51). Diferentemente do que ocorre com os animais, o processo de simbolização é natural do ser humano e ocorre a todo tempo, porque sempre estamos experienciando algo e, consequentemente, simbolizando. Segundo Langer (2004, p. 69), "a interpretação de signos é a base da inteligência animal," e portanto faz-se necessário compreender a diferença entre signos e símbolos. Langer (2004, p. 69) define signo como

a forma mais simples de conhecimento. Esta é, na verdade, a interpretação de signos. É o tipo mais elementar e mais tangível da intelecção a espécie de conhecimento que partilhamos com os animais, que adquirimos inteiramente por experiência, que possui óbvios usos biológicos, e igualmente critérios óbvios de verdade e falsidade.

Os signos, nesse sentido, representam as significações que utilizamos como respostas e/ou interpretações para algumas situações - como a cor vermelha do semáforo, que significa que o carro deve parar e, portanto, é o signo de "pare". A vida do ser humano é cercada por signos, e os animais também respondem a eles - como quando o dono de um cachorro mexe em sua vasilha de comida e o animal interpreta que é hora de comer; ou quando o dono pega a coleira e o animal interpreta que é hora de passear. Portanto, a resposta aos signos ocorre tanto no animal como no ser humano, apesar de a simbolização ocorrer somente no ser humano. Em relação aos símbolos, Langer afirma:

Os símbolos não são procuradores de seus objetos, mas veículos para a concepção de objetos. Conceber uma coisa ou uma situação não é o mesmo que "reagir com respeito a ela" abertamente, ou estar ciente da sua presença. Falando acerca de coisas; e são as concepções não as coisas, que os símbolos "significam"diretamente. (LANGER, 2004, p. 52, grifos da autora).

O signo remete diretamente ao objeto; o símbolo não, mas ele pode dar uma nova forma ao objeto, uma concepção mais pessoal. Susanne Langer (2004, p. 40-41), para exemplificar o modo como o ser humano utiliza os símbolos, parte do exemplo do nome de uma pessoa. Cada pessoa tem um 
nome, e muitas têm nomes iguais, mas, quando digo Maria, não me remeto a qualquer Maria, ou a todas as Marias, remeto-me à concepção da Maria que eu conheço, e essa concepção está carregada das minhas percepções dessa pessoa, além das várias relações que estabeleço com ela; é a simbolização que faço dessa Maria específica que conheço. Langer (2004, p. 52) explora mais aprofundadamente o assunto em seu livro Filosofia em Nova Chave (2004).

O cérebro [...] não para de fabricar ideias [...] está seguindo sua própria lei; está traduzindo ativamente experiências em símbolos, no cumprimento de uma necessidade básica de fazê-lo. Executa um constante processo de ideação [...]. A ideação procede por um princípio de simbolização. O material fornecido pelos sentidos é constantemente elaborado em símbolos, que são nossas ideias elementares. Algumas dessas ideias podem ser combinadas e manipuladas ao modo que denominamos "raciocínio". (grifos da autora).

No momento da experiência em si (experiência no aqui e agora, no presente), nossos sentidos estão alertas, recebendo as sensações que nos são provocadas. Algumas dessas sensações, carregadas de memórias de experiências passadas, são simbolizadas, ou seja, há um processo de conexão de diversas ideias - é o processo de simbolização que culmina em uma forma de expressão. É o organismo como um todo trabalhando para a formulação de ideias a partir da experiência vivenciada. Langer (2004, p. 54) afirma: "A fala é, de fato, a mais imediata terminação ativa desse processo básico no cérebro humano que podemos denominar transformação simbólica de experiências". Mas, apesar de Langer apontar a fala como uma das formas mais imediatas da transformação simbólica, a autora não a considera única, e retoma essa discussão trazendo a obra de arte também como uma forma de transformação simbólica, assinalando que "o ritual, como a arte, é essencialmente a terminação ativa de uma transformação simbólica da experiência" (LANGER, 2004, p. 55).

Ao colocar em debate a expressão gramatical, ou seja, a expressão pela linguagem (forma discursiva da expressão simbólica) como não sendo a única forma de expressão articulada, Langer abre caminho para a discussão sobre as expressões não discursivas - as quais não deixam de ser relevantes como expressão simbólica humana - e completa: "A linguagem não é de 
modo algum nosso único produto articulado" (LANGER, 2004, p. 96). Nossos órgãos dos sentidos (visão, tato, olfato, audição e paladar) nos provocam sensações relacionadas a emoções que não conseguimos expressar por meio de palavras, mas que podemos fazê-lo por meio da arte, do ritual, da religião etc. É o que Langer denomina de forma apresentativa da expressão simbólica. A expressão final do turbilhão de sensações e emoções que determinadas experiências nos provocam não consegue evidenciar tudo o que sentimos no momento da experiência, mas consegue expressar parte desse material de forma articulada; assim também acontece na linguagem verbal, que não expressa toda a experiência vivenciada, mas apenas parte dela, de forma articulada.

Nossa mais simples experiência sensorial é um processo de formulação. O mundo que realmente se apresenta aos nossos sentidos não é um mundo de "coisas", a cujo respeito somos convidados a descobrir fatos tão logo codificamos a linguagem lógica necessária para fazê-lo; o mundo da pura sensação é tão complexo, tão fluido e pleno, que a nua sensibilidade aos estímulos apenas se depararia com o que William James chamou (em frase característica) "uma zumbidora florescente confusão". Deste tumulto, os nossos órgãos do sentido precisam selecionar formas predominantes, se é que eles devem comunicar coisas e não meras sensações dissolventes. (LANGER, 2004, p. 96, grifos da autora).

A linguagem verbal não expressa tudo o que vivenciamos; entretanto, muito do que a linguagem verbal não consegue expressar é expresso pelas formas apresentativas. Essa seleção que os órgãos do sentido realizam, do tumulto de sensações que temos a todo momento, é o que vai levando a experiência a uma forma articulada. Dessa maneira, faço um esquema na tentativa de ilustrar a organização, passo a passo, da transformação da experiência em uma forma final, isto é, em uma expressão:

Experiência $=$ sensações $\rightarrow$ percepção $\rightarrow$ memória $\rightarrow$ simbolização $\rightarrow$ expressão (RAMALDES; CAMARGO, 2015).

Assim, a partir das experiências vividas, o indivíduo tem sensações, algumas das quais elaboradas em percepções que são retidas na memória. Essas memórias presentes se articulam com memórias de experiências 
passadas e são organizadas em formas simbólicas. Por sua vez, as formas simbólicas organizadas se transformam em uma expressão que poderá ser discursiva ou apresentativa (não discursiva). A expressão discursiva seria de compreensão lógica, como a linguagem verbal; já a expressão apresentativa seria não-discursiva, indizível, intraduzível, mais relacionada às produções artísticas, ao sentimento, às performances. Langer (2011, p. 411) completa: "Uma obra de arte é intrinsecamente expressiva; é destinada a abstrair e apresentar formas para a percepção - formas de vida e sentimento, atividade, sofrimento". Aqui, percebo a característica expressiva da obra de arte, não necessariamente uma expressão objetiva, mas uma expressão subjetiva.

Tão logo as formas naturais da experiência subjetiva sejam abstraídas ao ponto da apresentação simbólica, podemos utilizar essas formas para imaginar o sentimento e entender-lhe a natureza. $\mathrm{O}$ autoconhecimento, a introvisão de todas as fases da vida e da mente, surge da imaginação artística. Eis aí o valor cognitivo das artes. (LANGER, 1962, p. 89).

Langer apresenta a relevância da arte para a vida do ser humano, pois, segundo a autora, é a imaginação artística que ajuda o indivíduo a se conhecer melhor e a conhecer o mundo ao seu redor, porque essa é uma educação dos sentimentos. Langer (1962, p. 90) chega a afirmar que "um generalizado descaso pela educação artística equivale a descaso pela educação do sentimento". Bom seria se todo ser humano tivesse direito à democratização da educação estética e artística, uma vez que a influência exercida pela arte sobre a sua vida pode levá-lo a mudanças culturais radicais. A educação em arte trabalha diretamente com a maneira de sentir do indivíduo e com a articulação das diversas formas de sentir; portanto, se torna essencial a qualquer indivíduo ou civilização. Além disso, uma educação em arte leva o indivíduo à possibilidade de se expressar artisticamente, conduzindo-o também a ser um espectador de diversas artes.

Em relação às formas de percepção da obra de arte, Langer (2011, p. 410) afirma que "essa emoção real, que tem sido chamada de 'emoção estética', não é expressa na obra, mas pertence à pessoa que a percebe". Toda experiência está carregada de emoções, e a qualidade estética, por ser emocional, é que torna uma experiência completa. Ao entrar em contato com uma 
obra de arte, seja ao ler um livro ou ao assistir a uma peça teatral, a emoção se manifesta no espectador dessa obra, independentemente da emoção manifesta no artista no momento em que executou a obra. Quando o espectador entrar em contato com a obra de arte, utilizará as suas próprias experiências para se relacionar com ela, então, o que o espectador compreende da obra de arte está carregado de suas próprias subjetividades, suas simbolizações, suas concepções de mundo. Em muitos casos, as interpretações podem ser diversas da concepção do artista, da mesma forma que a compreensão de um segundo espectador poderá ser diferente da do primeiro. Cada indivíduo utilizará as suas próprias experiências passadas, tanto para compreender quanto para criar a obra. A obra de arte é constituída de emoções e de experiências do artista que a concebe, mas a interpretação do espectador também traz emoções e experiências que se articularão com a obra a fim de conseguir uma compreensão dela.

Dewey (2010, p. 59) afirma: "Visto que a obra de arte real é aquilo que o produto faz com e na experiência, o resultado não favorece a compreensão". O resultado, nesse caso, não favorece a compreensão literal ou teórica de uma obra de arte, pois a obra de arte é carregada de subjetividades do artista que a executou; mas a obra provoca no espectador algumas sensações que o induzem a algum tipo de compreensão daquela obra, na maioria dos casos uma compreensão subjetiva, mais ligada às sensações e às emoções, ou seja, uma significação não discursiva.

Entender a "ideia" em uma obra de arte é, portanto, mais como ter uma nova experiência do que como admitir uma nova proposição; e para agenciar este conhecimento por familiaridade, a obra pode ser adequada em certo grau. Não existem quaisquer graus de verdade literal, mas a verdade artística, que é toda significação, expressividade, articulação, possui graus; portanto, as obras de arte podem ser boas ou más, e cada uma deve ser julgada segundo nossa experiência de suas revelações. (LANGER, 2004, p. 259, grifos da autora).

Langer, no trecho citado, reforça a proposição, apontada por Dewey, de que a compreensão de uma obra de arte depende muito mais das experiências vividas pelo espectador do que da identificação das experiências do artista ali articuladas. Dewey (2010, p. 490) afirma: "quanto mais uma obra de 
arte incorpora aquilo que faz parte de experiências comuns a muitos indivíduos mais expressiva ela é.' Ela se torna mais expressiva porque a identificação com a obra é maior, já que ela está carregada de experiências comuns a todos os indivíduos. De fato, alguns espectadores serão mais sensibilizados pela obra, enquanto outros não serão.

Se a interpretação da obra de arte pelo espectador depende de suas experiências pessoais, para formar mais espectadores é necessário enriquecer suas experiências. Quanto mais experiências estéticas eles tiverem, mais capacidade de interpretação da obra de arte eles terão. Essa formação estética está diretamente ligada a conhecer e vivenciar a arte, por isso a relevância da disciplina Arte no currículo escolar. As pessoas necessitam ver, refletir, vivenciar e dialogar a arte; só desse modo poderão se enriquecer de experiências estéticas e críticas. Os espectadores que já têm conhecimento mínimo da arte teatral poderão ler um espetáculo de teatro com mais propriedade, se identificando ou não com ele. Não precisamos nos identificar com tudo o que assistimos.

Mas o que seria ler um espetáculo? Voltemos a esse termo também muito utilizado para referir à relação entre espectador e obra de arte. Para Pavis (2007, p. 227),

ler o espetáculo é, no sentido metafórico, decifrar e interpretar os diferentes sistemas cênicos* (dentre os quais o texto dramático*) que se oferecem à percepção do espetáculo. A crítica emprega hoje a expressão "ler o teatro" (UBERSFELD, 1977a) no sentido de uma busca de todas as unidades possíveis do texto e das imagens cênicas com a finalidade de "determinar os modos de leitura que permitem não só esclarecer uma prática textual muito particular, como mostrar, se possível, os vínculos que unem esta prática textual a uma outra prática, que é a de representação" (Ibid., p. 8). (grifos e asteriscos do autor).

A leitura do espetáculo, assim, está relacionada ao todo do espetáculo (texto, interpretação, ações, marcações, cenário, luz etc.), ou seja, tudo o que se oferece à percepção do espectador. Ingrid Dormien Koudela ${ }^{3}$ e José Simões de Almeida Júnior ${ }^{4}$ (2015, p.113) afirmam que:

3. Principal introdutora dos jogos teatrais no Brasil.

4. Pesquisador das áreas da pedagogia do teatro, do espaço teatral, da sociologia do teatro e da dramaturgia. 
[...] o espectador mobiliza não apenas sua capacidade perceptiva, mas também um conjunto de saberes, afetos e crenças, vinculados a um tempo histórico, às experiências sociais e às culturais em que está inserido. Desta forma, a leitura da imagem se encontra na situação de mediação entre a realidade e o espectador, o que determina o seu caráter intencional e seu valor de significação.

Mais uma vez temos aqui a vinculação entre a percepção do espectador sobre a obra e suas experiências pessoais. Desconsiderar a individualidade do espectador na leitura da obra é desconsiderar as múltiplas possibilidades de interpretação; é colocar o artista, criador da obra, como inatingível e detentor do saber.

Para Ana Mae Barbosa ${ }^{5}$ (1998, p. 40), "leitura da obra de arte é questionamento, é busca, é descoberta, é o despertar da capacidade crítica, nunca a redução dos alunos a receptáculos das informações do professor, por mais inteligentes que eles sejam." Entendem-se, aqui, alunos como espectadores e professor como artista; em vista disso, podemos compreender que o espectador não pode ser considerado como um receptáculo que receberá as ideias dos artistas prontas e acabadas, do modo como foram criadas. Existirá, sim, uma leitura crítica e questionadora dos espectadores sobre o que assistem.

Os termos interpretação e leitura, embora distintos, apresentam conceitos muito próximos, sendo que, na definição de cada conceito, aqui explanado, um abarca o outro. Relevante é perceber que, quando falamos de leitura ou interpretação, estamos dando um lugar à subjetividade do espectador, abrindo possibilidades para que a percepção do espectador seja considerada, sem induzi-lo a uma opinião necessariamente positiva da obra. Necessário se faz refletir sobre o papel do espectador na relação com a obra, que nos tempos atuais vem se tornando cada vez mais efetiva e participativa. Assim, considerar as percepções dos espectadores e a multiplicidade de significados que a obra pode abranger nessa relação é de fundamental importância. Nesse contexto, torna-se fundamental investir na formação de espectadores, para que cada vez mais os tenhamos nas nossas salas de espetáculos contribuindo com suas percepções particulares.

5. Educadora brasileira pioneira em arte-educação. 


\section{Referências bibliográficas}

BARBA, E.; SAVARESE, N. A arte secreta do ator: um dicionário de antropologia teatral. São Paulo: É Realizações, 2012.

BARBOSA, A. M. Tópicos utópicos. Belo Horizonte: C/Arte, 1998.

BORBA, F. S. (coord.). Dicionário gramatical de verbos do português contemporâneo do Brasil. São Paulo: Unesp, 1990.

CUNHA, A. G. Dicionário etimológico Nova Fronteira da língua portuguesa. Rio de Janeiro: Nova Fronteira, 1982.

DEWEY, John. Arte como experiência. Tradução Vera Ribeiro. São Paulo: Martins Fontes, 2010.

HOUAISS, A.; VILLAR, M. S. Dicionário Houaiss da língua portuguesa. Rio de Janeiro: Objetiva, 2009.

KOUDELA, I. D.; ALMEIDA JÚNIOR, J. S. (coord.). Léxico de pedagogia do teatro. São Paulo: Perspectiva, 2015.

LANGER, S. Ensaios filosóficos. Tradução Jamir Martins. São Paulo: Cultrix, 1962. Filosofia em nova chave. 2. ed. Tradução Janete Meiches e J. Guinsburg. São Paulo: Perspectiva, 2004.

Sentimento e forma. 1. ed. Tradução Ana M. Goldberger e J. Guinsburg. São Paulo: Perspectiva, 2011.

PAVIS, P. Dicionário de teatro. São Paulo: Perspectiva, 2007.

RAMALDES, K.; CAMARGO, R. C. A experiência viva (Erlebnis) e os jogos teatrais: aspectos visíveis e aspectos não-visíveis. 2015. Disponível em: <https:// performancesculturais.emac.ufg.br/p/3719-artigos>. Acesso em: 22 abr. 2016.

Recebido em 26/02/2016

Aprovado em 10/05/2016

Publicado em 30/06/2016 